\title{
EFFECT OF DEMOGRAPHIC VARIABLES ON OCCUPATIONAL STRESS AND THEIR COPING STRATEGIES
}

\author{
${ }^{1}$ Prof. Nandini Pandey, ${ }^{2}$ Dr. G. V. Kesava Rao
}

\section{Abstract:}

This study focuses on investigating the relationship between demographic variables \& occupational stress and the coping strategies adopted by employees to deal with it. Age, experience, and gender are used as demographic variables. Problem-oriented and emotion-oriented coping strategies are primarily investigated to understand their impact on coping stress. Two additional coping strategies related to emotion venting and consuming medicines were also studied. Data has been collected from a US based software development firm. An attempt was made to fit a regression model on health based coping strategy elements and the demographic variables. A relationship between various coping strategies adopted at managerial/non-managerial level is explored in this study. At gender level, various coping strategies and their interrelationship is investigated. The results indicate that at organization level, emotion-based coping strategies have a direct relationship with health. At managerial level, female employees adopt more of problem-oriented strategies compared to their male counterparts. Problem-oriented strategies are being adopted at managerial level further confirms that, male and female employees are more socialized in structural and instrumental thinking thereby adopting problem-oriented strategies. At non-managerial level, female employees adopt more of emotion-oriented strategies compared to their male counterpart. This further implies that at non-managerial level, male and female employees are socialized into conventional behaviour thereby relying on emotion-oriented strategies.

Keywords: Occupational Stress, Coping Strategies, Problem oriented coping strategies, Emotion oriented coping strategies

\section{INTRODUCTION}

\section{OCCUPATIONALSTRESS}

Occupational stress can be defined as the harmful physical and emotional responses that occur when the requirements of the job do not match the capabilities, resources, or needs of the worker. Job stress can lead to poor health and even injury.

The concept of job stress is often confused with challenge, but these concepts are not the same. Challenge energizes us psychologically and physically, and it motivates us to learn new skills and master our jobs. When a challenge is met,
Prof. Nandini Pandey,

Research Scholar

Bangalore, Karnataka.

Email:nandinimail@gmail.com

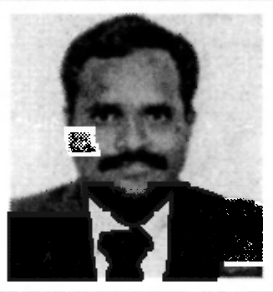

Dr. G. V. Kesava Rao, Professor and Dean (R\&D) Dept. of MBA and Research Center, RNS Institute of Technology, Bangalore, Karnataka. Email: drgvkr@gmail.com 
we feel relaxed and satisfied. Thus, challenge is an important ingredient for healthy and productive work. The importance of challenge in our work lives is probably what people are referring to when they say "a little bit of stress is good for the individual.

\section{Stress can involve:}

1. Physical effects, such as raised heart rate, increased sweating, headache, dizziness, blurred vision, aching neck and shoulders, skin rashes and a lowering of resistance to infection.

2. Behavioural and mental effects including increased anxiety and irritability, a tendency to drink more alcohol and smoke more, difficulty in sleeping, poor concentration, inability to deal calmly with everyday tasks and situations, a reduction in intellectual functioning and an impairment of creativity and problem solving skills.

These effects are usually short-lived and cause no lasting harm. When the pressures recede, there is a quick return to normal. Stress is not therefore the same as ill health. However, in some cases, particularly where pressures are intense and continue for some time, the effects of stress can be more sustained and far more damaging, leading to longer-term psychological problems and physical ill health.

\section{EFFECTS OF STRESS}

1. A person becomes overwhelmed and exhausted by a task.

2. A person's assessment of stressful situation is dysfunctional.

3. The person's coping skills are inadequate to address perceived stressors.
4. External resources are either not available or are insufficient.

Stress offers a wide spectrum of consequences. They include mood and sleep disturbances, upset stomach and headache, and disturbed family or friend relationships. These early signs of job stress are easy to recognize. But the conditions do not stop there. Studies also show that job stress leads to diseases, which may accumulate for a long period of time. These chronic diseases and conditions include cardiovascular diseases, musculoskeletal disorders, psychological disorders, workplace injuries, suicide, cancer, ulcers, and impaired immune functions

\section{ORGANISATIONAL IMPLICATIONS}

To certain extent, stress is unavoidable characteristic of life and work and as such, is neither inherently bad nor destructive occupational stress can have a negative impact on the well being of the individual and his or her day to day activities This is observed at a physical level (e.g. exhaustion, headaches, high blood pressure), a psychological level (e.g. depression, anxiety, low self esteem), a cognitive level (e.g. absent mindedness, poor memory), and a behavioural level (e.g. absenteeism, attrition, aggressive behaviour). An individual who is stressed will be exhibiting various unique features and behaviour. The organizational stress in individuals will manifest in various forms and the following are the most common implications of organisational stress in individuals.

1. Absenteeism - Is a habitual pattern of absence from work.

2. Increased Turnover - Is the rate at which individuals quit an organisation at a given 
time. If the occupational stress is very high in an organisation, then the turnover is high.

3. Decreased Productivity - Productivity is the input and the output ratio of an individual. If an individual is stressed, then the obvious effect would be that his or her productivity will decrease.

4. Low Morale - Morale is defined as the capacity of a group of people to pull together persistently and consistently in pursuit of a common purpose. If the stress levels of individuals are high, then obviously the morale also is down.

5. Decreased Creativity - Creativity is a mental and social process involving the generation of new ideas or concepts or new associations of the creative mind between existing ideas or concepts. A stressed mind cannot be effectively creative.

\section{REVIEW OF LITERATURE}

There has been a lot of focus in recent times as to how people cope with occupational stress. One of the earlier researches done in the area is by Lazarus (1966) and also by Lazarus and Folkman (1984). Lazarus argues that stress management is a three stage process. He termed the process of recognizing stress as primary appraisal and the process of making the mind ready for the response as secondary appraisal. Third stage is coping which is implementation of the response. Lazarus further emphasized that all the three steps work in a continuous tandem with a feedback loop to previous stages. For example, if the coping response is available, the person may reappraise the stress as low threat. Also if the coping response is expected to be less ineffective, the person may go back to the secondary appraisal for appropriate response. The entire process can go back and forth in a cycle during the stress situation.

Lazarus and Folkman (1980) developed a method to investigate the coping process. The measure is based on people thought and action when they undergo stress situations. The response to the stress (coping strategy) is generally categorized into two: problemfocused and emotion-focused. Problemfocused aims to eliminate the source of stress. This is predominant when people believe that something constructive can be done. Emotionfocused aims at managing/reducing the emotional suffering during to stress. This is predominant when people believe that stress must be tolerated. The two coping strategies are important however researchers have found additional coping responses to the stress apart from these two (Coyne, Aldwin and Lazarus, 1981; Lazarus and Folkman, 1985; Carver, Scheier and Weintraub, 1986). Researcher's opinion is that the additional stress response is extension of emotion-focused coping.

Problem-focused coping strategy has been considered to be more acceptable of the two as it tries to eliminate stress rather than managing it (Lazarus and Folkman, 1984). This helps employees in an organization to resist occupational stress rather than getting impacted by it emotionally (Allie, Bhagat et al., 1991). Muhonen and Torkelson (2003) however found that, there is no relationship between health and problem-focused coping strategies. Ashford (1988) argued that in some scenarios, problem-focused strategy actually increased stress rather than decreasing it. Further, many researchers have found difference in coping strategy adopted by men and women. Men are more inclined to use problem-focused coping strategy (Folkman and 
Lazarus, 1980) and women emotion-focused coping strategy (Carver, 1989; Hurst and Hurst, 1997; Helgeson and Janicki, 2002). Also men sometimes resort to alcohol/drug use for managing stress (Carver et al., 1989). However, some authors have reported no difference in coping strategy by gender (Parkes, 1990; Allie, Bhagat et al., 1991).

It is argued by Kahn and Long (1993) that those findings in which men use more of problemfocused coping strategy than women are attributed to cases when men and women are not matched at organizational level. They concluded that there should be no difference in coping strategy between men and women if they are at the same organizational level. Long (1990) further argues that research showing gender bias in coping strategy is due to genderrole stereotyping. Coping strategy is related to availability of power and resources in an organizational setup (Long and Cox, 2000; Banyard et al., 1993). Greenglass (2002) maintains that few differences in coping strategy can be found if gender, organization level and education are controlled. Emotionfocused coping strategy is more commonly observed at lower-level and problem-focused at higher-level in an organization (Menon et al., 1999).

\section{NEED FOR THE STUDY}

In this research paper, coping strategies of men and women employees who work at managerial/non-managerial level were studied in a software development firm. Also an attempt is made to develop a linear regression model on health based on coping strategies and demographic variables. The managerial role primarily focuses on project management, team management, and client management. Non-managerial role focuses on software development life cycle (requirement gathering, coding, testing, implementation, training and documentation). The key objective of the research is to analyze the relationship between coping strategies and occupational stress.

\section{RESEARCH METHODOOGY}

\section{STATEMENT OF THE PROBLEM}

Occupational stress exhausts an employee and makes him dysfunctional; unless it is overcome the efficiency will not improve. There is no universal method of coping stress that will be useful under all circumstances and at all levels. Therefore the coping strategies may vary depending on the demographical variables such as age, experience, gender and managerial or organizational position etc. This study is aims at studying the coping strategies adopted by employees in an organization.

\section{OBJECTIVE OF THE STUDY}

To study the various coping strategies adopted by employees in managing occupational stress and to find out the differences if any, in coping strategies adopted by employees in terms of their gender and position.

\section{SOURCES OF DATA}

Primary data has been collected from an organization which is an US based software development company through internet during the researcher's stay in US. And secondary data has been collected from various journals, newspaper, articles etc.,

\section{COLLECTION OF DATA}

A structured questionnaire has been administered covering the demographic variables and also COPE inventory developed by Carver to the employees of the organization. 


\section{SAMPLING}

A stratified random sampling method has been applied keeping the managerial and nonmanagerial ratio of the firm. The population is around 500 employees and the ratio between managerial and non-managerial is $1: 8$. Accordingly the data has been collected from 25 managerial personnel consisting of 16 male and 9 female employees and 75 nonmanagerial consisting of 53 male and 22 female employees. However, only 74 questionnaires had full responses to the questionnaire. The response rate for managers is $64 \%$ where as non-manager is $77 \%$.

\section{ANALYSIS OF DATA}

Ten different coping strategies were selected for measurement out of 14 present in the COPE. inventory. In ten, four are used for measuring problem-focused coping strategy, another four are used for emotion-focused coping strategy, and the remaining two are additional coping strategies used for analysis.

The list is summarized below:

Problem-focused coping strategies

I Active coping

ii. Planning

iii. Suppression of competing activities

iv. Seeking social support for instrumental reasons

Emotion-focused coping strategies

I Seeking social support for emotional reasons

ii. Positive interpretation and growth

iii. Acceptanceiv. Denial

Two additional coping strategies

1 Focus on venting of emotions

ii. Use of medicines (drug/alcohol)
Coping strategy one through nine is measured with four items using a single item question. The tenth strategy is measured using a singleitem question. The reliability coefficient for the ten coping strategies ranged from 0.67 to 0.75 (refer Table 1).

Health was measured using Hopkins Symptom Checklist-25 (Lipman, Covi et al., 1974) whose validity and reliability has been concluded by authors as satisfactory. The checklist consists of 25 items measuring health related symptoms such as headache, sleeplessness, feeling of hopelessness, nervousness, anxiety, uncertain future, and increased heart rate. The response is measured on a four point scale (not concerned to extremely concerned). The reliability coefficient for health is reported as 0.70 (refer Table 1).

\section{HYPOTHESES}

The set of hypothesis to be tested have been summarized below:

- Hypothesis 1: There is no difference in coping strategies between male and female employees.

- Hypothesis 1a: There is no difference in coping strategies between male and female employees at non-managerial level.

- Hypothesis $1 \mathrm{~b}$ : There is no difference in coping strategies between managerial and non-managerial level for male employees.

- Hypothesis 2: There is no difference in coping strategies between managerial and non-managerial level.

- Hypothesis 2a: There is no difference in coping strategies between male and female employees at managerial level. 
Hypothesis $2 b$ : There is no difference in coping strategies between managerial and non-managerial level for female employees.

\section{LIMITATIONS OF THE STUDY}

1. One of the limitations of the study is its sample size. With size of 75 , some of the possible relationship between elements could not be established with confidence.

The data is from a US based software development company. Generalization to other countries may not yield satisfactory results.

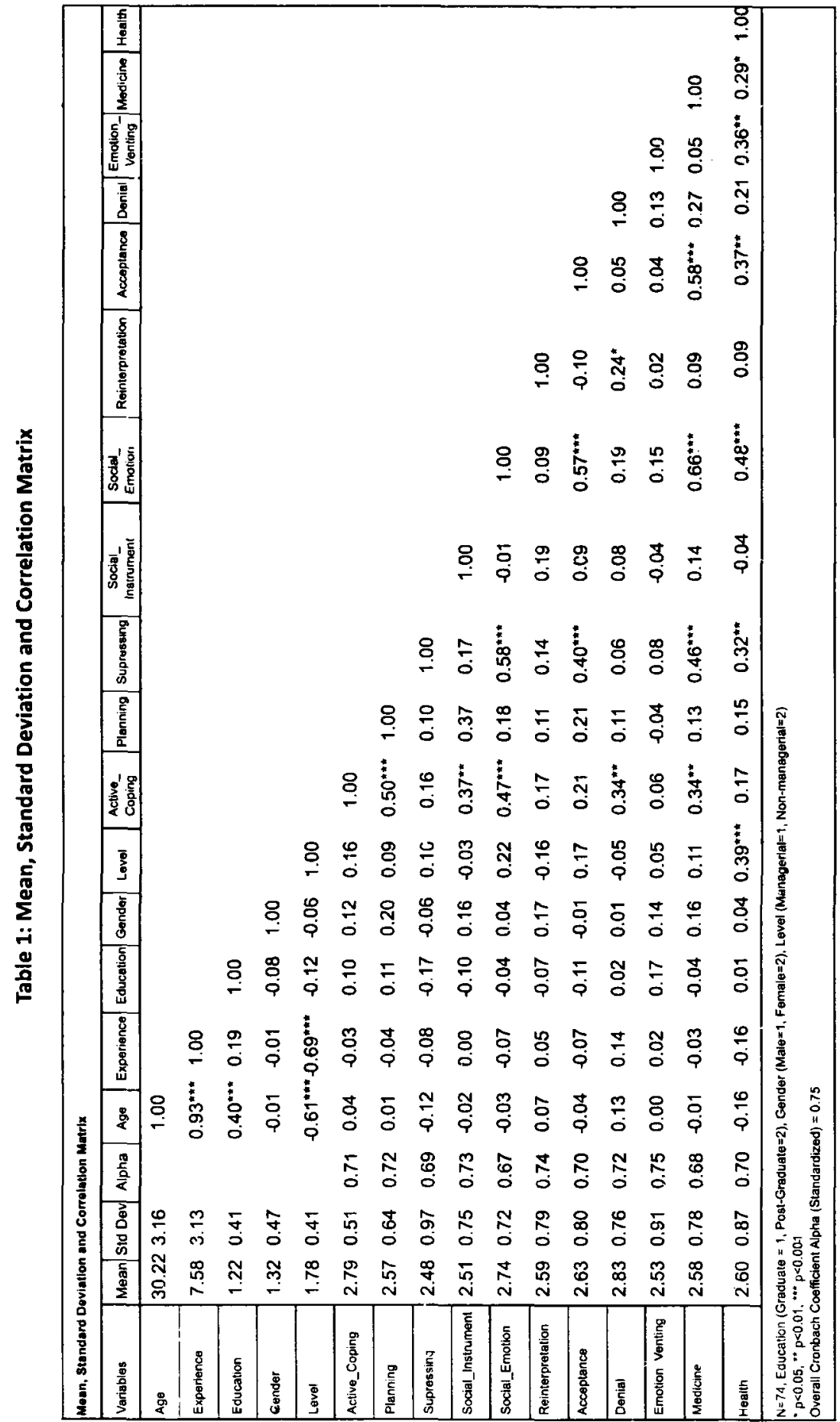




\section{FINDINGS}

The Mean, Standard Deviation and Correlation Matrix of the variables are shown in Table 1 . The mean and standard deviation for variables Education, Gender and Level are low mainly because they are two-item questions.

The correlation between health and other demographic variables were found to be insignificant. A high degree of correlation is observed between different problem-focused strategies. Also few elements of problem focused strategies (Active Coping and Suppression of competing activities) were found to be significantly correlated with few elements of emotion-focused strategies (Seeking social support for emotional reasons, Acceptance, and Denial).

Two additional strategies (Taking medicine to manage stress and Venting of Emotions) were also analyzed. It was found that two elements of problem-focused strategies (Active coping and Suppression of competing activities) were significantly correlated with Taking medicine to manage stress. Also two elements of emotionfocused strategies (Seeking social support for emotional reasons and Acceptance) were significantly correlated with Taking medicine to manage stress.

One element from problem-focused strategy (Suppression of competing activities) was found to be significantly correlated with Health. From emotion-focused strategy, two elements (Seeking social support for emotional reasons and Acceptance) were found to be significantly correlated with Health. Apart from these, the two additional strategies (Taking medicine to manage stress and Venting of Emotions) were also found to have a significant correlation with Health.
A regression model on Health has been analyzed in Table 2 . The variable $p$ value, $R$ square value and $F$ test value have been shown. In the first step the demographic variables of experience and educational level were entered. Age and Experience were highly correlated (0.93) hence only Experience was entered in the model. Age and Experience couldn't establish any association with health problems. In second step, gender and organizational level was entered into the model. Overall the model converged with organizational level being the significant variable. R-square was observed to be $15 \%$.

In third step, it was hypothesized that problemfocused strategies combined with other two additional strategies could have an impact on health problems. However, it was observed that none of the four elements of problem-focused strategies were significant in third step. From the additional two strategies, one of them (focus on venting of emotion) was found to be the only significant element. R-square was observed to be $28 \%$.

In fourth step, it was hypothesized that emotion-focused strategies combined with other two additional strategies could have an impact on health problems. One element from emotion-focused strategy (Seeking social support for emotional reasons) and another element from two additional strategies (focus on venting of emotion) were observed to have a significant impact on health problems. Rsquare was observed to be $36 \%$.

In the fifth step, all the 10 strategies (four problem-focused, four emotion-focused and two additional strategies) entered the model. One element from emotion-focused strategy (focus on venting of emotion) and one from two additional strategies (focus on venting of 
emotion) were found to be significant. Rsquare increased marginally to $38 \%$.

In the sixth and final step, the significant elements from previous steps were selected and entered in the model. The final three significant elements were - Organizational level, Seeking social support for emotional reasons and Focus on venting of emotion. The model converged with R-square value of $40 \%$.

Table 2: Modeling Health

\begin{tabular}{|c|c|c|c|c|}
\hline Step & Variable entered & p value & R Square & F Test \\
\hline 1 & Experience & 0.17 & \multirow{2}{*}{0.03} & \multirow{2}{*}{0.38} \\
\hline & Education & 0.74 & & \\
\hline & & 550 & \multirow{3}{*}{0.15} & \multirow{3}{*}{0.003} \\
\hline 2 & Vence & 0.09 & & \\
\hline & & & & \\
\hline \multirow[t]{6}{*}{3} & Active coping & 0.78 & \multirow{6}{*}{0.28} & \multirow{6}{*}{0.001} \\
\hline & Planning & 0.20 & & \\
\hline & Suppression of competing activities & 0.06 & & \\
\hline & $\begin{array}{l}\text { Seeking social support for instrumental } \\
\text { reasons }\end{array}$ & 0.17 & & \\
\hline & Focus on venting of emotions & $0.002^{*}$ & & \\
\hline & Use of medicines & 0.19 & & \\
\hline & & & & \\
\hline \multirow[t]{6}{*}{4} & $\begin{array}{l}\text { Seeking social support for emotional } \\
\text { reasons }\end{array}$ & $0.009^{*}$ & \multirow{6}{*}{0.36} & \multirow{6}{*}{0.0001} \\
\hline & Positive interpretation and growth & 0.56 & & \\
\hline & Acceptance & 0.11 & & \\
\hline & Denial & 0.29 & & \\
\hline & Focus on venting of emotions & $0.006^{*}$ & & \\
\hline & Use of medicines & 0.36 & & \\
\hline \multirow{11}{*}{5} & & & \multirow{11}{*}{0.38} & \multirow{11}{*}{0.0005} \\
\hline & Active coping & 0.32 & & \\
\hline & Planning & 0.28 & & \\
\hline & Suppression of competing activities & 0.71 & & \\
\hline & $\begin{array}{l}\text { Seeking social support for instrumental } \\
\text { reasons }\end{array}$ & 0.67 & & \\
\hline & $\begin{array}{l}\text { Seeking social support for emotional } \\
\text { reasons }\end{array}$ & $0.03 *$ & & \\
\hline & Positive interpretation and growth & 0.58 & & \\
\hline & Acceptance & 0.19 & & \\
\hline & Denial & 0.21 & & \\
\hline & Focus on venting of emotions & $0.006^{*}$ & & \\
\hline & Use of medicines & 0.43 & & \\
\hline \multirow{4}{*}{6} & & & \multirow{4}{*}{0.40} & \multirow{4}{*}{$<0.0001$} \\
\hline & Organization Level & $0.004^{*}$ & & \\
\hline & $\begin{array}{l}\text { Seeking social support for emotional } \\
\text { reasons }\end{array}$ & $0.0002 *$ & & \\
\hline & Focus on venting of emotions & $0.003^{*}$ & & \\
\hline \multicolumn{5}{|c|}{$(*$ significant at $p<0.05)$} \\
\hline
\end{tabular}


Further aim of the study was to investigate various coping strategies.

Hypothesis and their results have been summarized in Table 3.

Table 3: Coping strategy hypothesis results

\begin{tabular}{|c|c|c|c|c|c|c|}
\hline $\begin{array}{l}\text { Sl. } \\
\text { No. }\end{array}$ & Hypothesis & $\begin{array}{l}\text { Sample } \\
\text { Size }\end{array}$ & $\begin{array}{l}\text { Significant } \\
\text { Elements }\end{array}$ & F Test & Mean & Std Dev \\
\hline 1 & $\begin{array}{l}\text { There is no difference } \\
\text { in coping strategies } \\
\text { between male and } \\
\text { female employees }\end{array}$ & 74 & None & NA & NA & NA \\
\hline 2 & $\begin{array}{l}\text { There is no difference } \\
\text { in coping strategies } \\
\text { between managerial } \\
\text { and non -managerial } \\
\text { level }\end{array}$ & 74 & None & NA & NA & NA \\
\hline $1 \mathrm{a}$ & $\begin{array}{l}\text { There is no difference } \\
\text { in coping strategies } \\
\text { between male and } \\
\text { female employees at } \\
\text { managerial level }\end{array}$ & 16 & Planning & 0.03 & $\begin{array}{c}\text { Male: } 2.35 \\
\text { Female: } 2.67\end{array}$ & $\begin{array}{c}\text { Male: } 0.41 \\
\text { Female: } 0.96\end{array}$ \\
\hline lb & $\begin{array}{l}\text { There is no difference } \\
\text { in coping strategies } \\
\text { between male and } \\
\text { female employees at } \\
\text { non-managerial level }\end{array}$ & 58 & Acceptance & 0.03 & $\begin{array}{c}\text { Male: } 2.67 \\
\text { Female: } 2.74\end{array}$ & $\begin{array}{c}\text { Male: } 0.88 \\
\text { Female: } 0.54\end{array}$ \\
\hline $2 a$ & $\begin{array}{l}\text { There is no difference } \\
\text { in coping strategies } \\
\text { between managerial } \\
\text { and non -managerial } \\
\text { level for male } \\
\text { employees }\end{array}$ & 50 & None & NA & NA & NA \\
\hline $2 b$ & $\begin{array}{l}\text { There is no difference } \\
\text { in coping strategies } \\
\text { between managerial } \\
\text { and non-managerial } \\
\text { level for female } \\
\text { employees }\end{array}$ & 24 & None & NA & NA & NA \\
\hline
\end{tabular}


From Table 3 , it is observed that coping strategy and gender are not related (hypothesis 1). Male and female employees at the overall level deal with stress in similar manner. Also it is found at overall level managers and non-managers deals with stress in the same way (hypothesis 2). Organization level was kept as blocking factor for next two hypotheses. At managerial level, male and female employees have different coping strategies (hypothesis 1a). Female employees focused more on planning (mean=2.67) compared to male employees (mean=2.35). At non-managerial level also it is observed that male and female employees have different coping strategies (hypothesis 1b). Female employees focused more on Acceptance (mean=2.74) compared to male employees (mean=2.67). For the next two hypotheses, gender was kept as the blocking factor. For male employees, it was observed that there is no difference in coping strategy between managerial and non-managerial level (hypothesis 2a). Similarly for female employees, it was observed that there is no difference in coping strategy between managerial and non-managerial level (hypothesis 2b).

\section{CONCLUSION}

From the study, it is evident that problemfocused strategies to handle stress has very low or no impact on health. Organization level along with emotion-focused strategy (seeking social support for emotional reasons) and one additional strategy (focus on venting of emotions) are found to have impact on health. Demographics variables such as gender, age and experience at overall level had no significant impact on stress.

At managerial level, the hypothesis that male and female employees who are the same level in the organization and do similar work use problem focused strategy to cope stress was supported to some extent (long and Kahn 1992). Male employees at managerial levei use more of planning based coping strategies as compared to female managers. However at non-managerial level, the hypothesis was not supported as we observed that emotionfocused strategy is more evident in coping stress (in line with Carver et al 1989). Female employees at non-managerial level used more of emotion based coping strategies to handle stress compared to male employees at nonmanagerial level. Similar results were also observed by Korabik and McDonald (1991). One justification of the findings is that at managerial level, male and female employees are more socialized in structural and instrumental thinking thereby adopting problem-oriented strategies. However at nonmanagerial level, male and female employees are socialized into conventional behaviour thereby relying on emotion-oriented strategies.

One of the limitations of the study is its sample size. With size of 75 , some of the possible relationship between elements could not be established with confidence. Second, the data is from a US based software development company. Generalization to other countries may not yield satisfactory results. In summary, organization level and emotion-based coping strategies have a direct relationship with health. At managerial level, female employees adopt more of problem-oriented strategies compared to their male counterparts. It implies that problem-oriented strategy is being adopted at managerial level. At non-managerial level, female employees adopt more of emotion-oriented strategy compared to their male counterpart. It implies that emotionoriented strategy is being adopted at nonmanagerial level. 


\section{BIBLIOGRAPHY}

Aldwin, C., and Revenson, T. A. (1987). "Does coping help?" $A$ reexamination of the relation between coping and mental health. Journal of Personality and Social Psychology, 53, pages 337-348.

Ashford, S. J. (1988). "Individual strategies for coping with stress during organizational transitions", The Journal of Applied Behavioral Science, 24(1), pages 19-36.

Banyard, V. L. and Graham-Bermann, S. A. (1993). "Can women cope?" Psychology of Women Quarterly, 17, pages 303-318.

Bhagat, R. S., Allie, S. M., and Ford, JR., D. L. (1991). "Organizational stress, personal life stress and symptoms of life strain: An inquiry into the moderating role of styles of coping", Journal of Social Behavior and Personality, 6(7), pages 163-184.

Breznitz, S. (Ed.). (1983). "The denial of stress", New York: International Universities Press.

Carver, C. S., Scheier, M. F., and Weintraub, J. K.
(1989). "Assessing coping strategies: A theoretically based approach", Journal of Personality and Social Psychology, 56, pages 267-283.

Christie, M. D. and Shultz, K. S. (1998). "Gender differences on coping with job stress and organizational outcomes", Work \& Stress, 12, pages 351-361.

Derogatis, L. R., Lipman, R. S., Rickels, K., Uhlenhuth, E. H., and Covi, L. (1974). "The Hopkins symptom checklist (HSCL): A selfreport symptom inventory", Behavioral Science, 19, pages 1-15.

Dewe, P, Cox, T., and Ferguson, E. (1993). "Individual strategies for coping with stress at work: A Review", Work \& Stress, 7(1), pages 5-15.

Folkman, S., and Lazarus, R. S. (1985). "If it changes it must be a process: A study of emotion and coping during three stages of a college examination", Journal of Personality and Social Psychology, 48, pages 150-170. 